\title{
Reinaré en España. La devoción al Sagrado Corazón de Jesús
}

\section{Will Reign in Spain: Devotion to the Sacred Heart of Jesus}

\author{
María Antonia Herradón Figueroa \\ Museo del Traje. \\ Centro de Investigación del Patrimonio Etnológico. Madrid
}

\section{RESUMEN}

El culto al Sagrado Corazón de Jesús, aún implantándose de forma casi oficial en la España de 1733, no adquirió pleno desarrollo en nuestro país hasta el ochocientos, centuria calificada por muchos autores como "El Siglo del Sagrado Corazón de Jesús". No obstante, su momento de máximo esplendor se alcanzaría entre 1900 y 1970, período en el que se sucedieron sin solución de continuidad numerosas iniciativas encaminadas a reforzar la devoción.

Palabras clave: Religión católica, Sagrado Corazón de Jesús, Detentes, Escapularios, Escudos, España.

\section{SUMMARY}

Though started in a quasi-official manner in 1773 , the cult in Spain to the Sacred Heart of Jesus did not begin in earnest till the 1800s, to the extent that such century came to be called "The century of the Sacred Heart of Jesus." The cult reached its apogee in the period from 1900 to 1970 , as the result of many initiatives that were designed to spread it.

Key words: Catholic Religion, Sacred Heart of Jesus, Detentes, Scapulars, Shields, Spain.

\section{INTRODUCCIÓN}

Si prescindimos de las referencias que, dentro y fuera de nuestras fronteras, recogen los manuales de historia de la Iglesia y las historias del catolicismo acerca del culto al Sagrado Corazón de Jesús, los trabajos que se han dedicado a este asunto en lengua castellana son escasos y poco rigurosos. Sin embargo, encontramos multitud de impresos centrados en el tema 
que nos ocupa, promovidos, alentados y cultivados por asociaciones religiosas o autoridades eclesiásticas. Entre ellos merecen una mención especial las publicaciones periódicas, cuyo número y pervivencia a lo largo del tiempo constituyen el mejor testimonio de la fortaleza y del arraigo de una devoción que muchos califican como netamente española. Por ello pensamos que estas revistas son de obligada consulta, no tanto por el valor intrínseco de sus contenidos — discutible en la mayoría de las ocasiones-, como por su condición de formidable máquina propagandística, garantía de la difusión uniforme y absoluta del culto proclamado.

La decana es El mensajero del Sagrado Corazón de Jesús: boletín mensual del Apostolado de la Oración, publicada sin interrupción entre 1866 y 1953. Le sigue en antigüedad El Corazón de Jesús en el Tibidabo, fundada en 1906 y precursora de Tibidabo, órgano mensual del Templo Nacional Expiatorio del Tibidabo, editada entre 1961 y 1987. Y Reinado Social del Sagrado Corazón: revista mensual e ilustrada dirigida por los Padres de los Sagrados Corazones, fundada en 1917 y editada hasta la Guerra Civil. En el último lugar figura Reinaré en España, órgano del Santuario Nacional de la Gran Promesa en Valladolid, que vio la luz en 1937 y que, con el tiempo y hasta su desaparición en los años 70, acabaría convirtiéndose en el portavoz de los tres santuarios españoles dedicados al Sagrado Corazón de Jesús.

En cuanto al resto de bibliografía, Ortega Ayuso publicó en 1959 una exhaustiva compilación, quizás la más rigurosa de cuantas se habían realizado hasta la fecha.

En su conjunto, estos documentos tienen el enorme valor de haber actuado como intermediarios entre las proclamaciones doctrinales emitidas desde el Vaticano en forma de encíclicas y cartas apostólicas, o por la curia de la Iglesia española en forma de pastorales, y el lenguaje físico, más obvio y comprensible, propio de los elementos materiales que acabaron dando forma en España al culto del Sagrado Corazón de Jesús. Pueden considerarse, en definitiva, como una especie de manual de instrucciones, a través del cual fueron tomando carta de naturaleza una serie de objetos que ya han pasado a formar parte de las colecciones de nuestros museos pero que, al mismo tiempo, en buena medida han permanecido in situ. De ahí que las referencias a sus contenidos abunden en el análisis del tema que realizamos a continuación.

\section{CONTEXTO HISTÓRICO}

El culto al Sagrado Corazón de Jesús goza en España de una sólida tradición. Sus orígenes como devoción de carácter público se remontan al año de 1733 y están ligados a la figura del jesuita Bernardo de Hoyos, principal 
impulsor de las misiones, intensivas campañas de predicación que extendieron entonces esta nueva orientación de la piedad por todo el territorio nacional. En aquella fecha el Padre Hoyos fue, al parecer, objeto de una aparición de Jesucristo, convirtiéndose como consecuencia en depositario de la Promesa - a la que numerosos textos y autores se refieren como la "Gran Promesa" - que indeleblemente acabaría ligando la figura del nuevo Cristo misericordioso, que muestra su corazón, con nuestro país. El voto afirmaba lo siguiente: "Reinaré en España y con más veneración que en otras partes".

En realidad, la historia oficializada del Sagrado Corazón de Jesús se había iniciado en Francia un siglo antes del mencionado suceso. Margarita María Alacoque, monja del convento de la Visitación de Paray-le-Monial, fue privilegiada con la aparición de Jesucristo mostrando su corazón en el pecho abierto. La religiosa se convirtió en transmisora de sus deseos de instituir un culto en su honor y, al mismo tiempo, en depositaria de una serie de promesas que redundarían en sus devotos. Este hecho debe, pues, considerarse el genuino punto de partida de un movimiento que, consagrado formalmente en 1685, coincidía plenamente con la política del catolicismo romano de la época, que quería afirmar mediante el símbolo ${ }^{1}$ del corazón abierto -y como oposición al protestantismo y al jansenismo- el amor de Dios hacia todos los hombres sin excepción (Réau 1983: 48).

Durante todo el siglo XVIII, y siempre de la mano firme de los miembros de la Compañía de Jesús, se pusieron en marcha en España diversas iniciativas encaminadas a extender y afirmar la devoción al Sagrado Corazón. Parece claro que la Corona se sumó a esta corriente desde el primer momento, lo que no debe causar extrañeza si se consideran los antecedentes establecidos por Felipe V: ya en 1727, aunque es verdad que con escasa fortuna, el primer monarca español de la Casa de Borbón había solicitado del Papa Benedicto XIII ciertos privilegios para el desarrollo y engrandecimiento de este culto en su reino ${ }^{2}$.

\footnotetext{
${ }^{1}$ Con respecto al corazón afirma Pérez-Rioja lo siguiente: "Su posición central en el cuerpo humano otorga al corazón el privilegio de absorber o concentrar en la imaginación popular la idea de otros dos puntos fundamentales: el cerebro y el sexo. El corazón, situado entre ambos, viene a ser, en general, el símbolo del sentimiento, del amor, del coraje. Así, se ha considerado desde siempre como la fuente de la comprensión, el amor, el valor, el dolor o la alegría. En un aspecto amplísimo — religioso y profano- el corazón es un símbolo universal de amor: ya de caridad cristiana o de amor al prójimo, ya de amor humano o de sentimiento amoroso, porque amar es un impulso hacia un objeto que es centro de todas las inclinaciones del que ama, y el corazón es como el centro o la palanca que impulsa el motor humano" (1984: 138).

${ }^{2}$ La carta remitida a Roma por Felipe V figura en el colofón del texto de Juan de Loyola (1831: 189-191) y reza así: "Beatísimo Padre: Deseando por mi parte concurrir á
} 
El círculo de jesuitas más próximo al Padre Hoyos llevó hasta la corte el mensaje de la recién estrenada devoción, la cual parece que prendió con rapidez entre príncipes, nobles y cortesanos, de manera que en 1737 ya se pudo fundar una primera asociación de fieles particularmente sensibles a la nueva piedad. Desde entonces fueron muy numerosas las congregaciones devotas constituidas en todo el país a imagen y semejanza de la pionera. Es indiscutible que, como nos recuerda Uriarte (1880: 325),

el ejemplo de la corte [fue] un aliciente poderoso, una obligación sagrada para las demás ciudades, ya que España entera se volcó con celeridad y entusiasmo en la figura del Sagrado Corazón de Jesús. El éxito fue tan clamoroso que en 1765, con una diligencia inusitada para las costumbres del Vaticano, el papa Clemente XIII aprobó oficialmente el novel movimiento.

Pero fue a lo largo del siglo XIX —una vez superado el bache provocado por la expulsión de los jesuitas de nuestro territorio- cuando puede considerarse definitiva su consolidación, tanto es así que esta centuria ha sido denominada por algunos autores "siglo del Sagrado Corazón de Jesús"3. Muy pronto Fernando VII obtuvo, por fin, de Roma la autorización para celebrar su fiesta en todos los territorios de la Corona española, así como la potestad para fundar una cofradía en su honor y otros privilegios, concesiones que, en su conjunto, contribuyeron al resurgimiento del culto. Varias estampas conservadas en el Museo Municipal de Madrid dan fe del impulso auspiciado por nuestros monarcas. Una de ellas —firmada por Vicente López, pintor de cámara de Fernando VII - fue abierta a expensas de la congregación que, con el título de Real, había sido fundada en 1826. Además, la ilustración constituye el complemento visual de un prolijo texto que consideramos muy significativo: se trata de unos Versos compuestos por la reina Maria Josefa Amalia al Sagrado Corazón de Jesús . Parece evidente, pues, que por entonces la figura del Sagrado Corazón ya estaba colocada bajo la tutela personal del rey y su entorno más inmediato.

que se extienda y propague la devoción al Divino Corazón de Jesús, estoy persuadido, à que esto se facilitará concediendo V. Santidad para todos mis reinos y dominios Misa y Oficio propio suyo. Por lo que fiado en el paternal amor de V. Beatitud, paso á suplicar á V. Santidad con las mayores veras y empeño, se sirva de dispensarme esta gracia que espero merecerle, [...]".

${ }^{3}$ El siglo XIX también se conoce como "siglo de la Inmaculada Concepción", cuyo dogma fue proclamado en 1854 por Pío IX, también llamado por esta circunstancia "papa de la Inmaculada".

${ }^{4}$ M. ${ }^{\underline{a}}$ Josefa Amalia de Sajonia fue la tercera esposa de Fernando VII. La historia dice de ella que fue extraordinariamente devota y muy aficionada a la poesía, rasgos que quedan confirmados con lo apuntado aquí. Murió en 1829. 
En casi todos los grabados de esta época se repite el mismo motivo iconográfico: un corazón, rodeado de una corona de espinas, con una llaga sangrante en el lado derecho, y coronado por una cruz, rodeada, bien de luz o de rayos, bien de llamas. Como complemento, un grupo de ángeles enmarca el conjunto. Es la prueba de que, si ya entonces era conocida, la imagen de Cristo sosteniendo o señalando su corazón, todavía no había echado raíces en el repertorio de la imaginería católica. Más adelante dedicaremos un epígrafe específico a algunas de las cuestiones iconográficas relacionadas con el asunto.

En los años centrales del siglo xIx la devoción fue promovida de manera especialmente entusiasta desde el Vaticano, sobre todo por Pío IX, que recibió por ello el sobrenombre de "papa del Sagrado Corazón” (Queralt Teixidó 2001). Así, en 1846, justo cuando se iniciaba su pontificado, el Papa aprueba la creación del Apostolado de la Oración, que había sido fundado en Francia por el jesuita Henri Ramière y que acabaría erigiéndose en el principal núcleo impulsor de la corriente. Según sus estatutos (Apostolado 1960: 8), esta piadosa unión de fieles:

[...] promueve por todos los medios la devoción al Sagrado Corazón de Jesús. Impulsa a los asociados a que se formen en el espíritu de esta devoción y practiquen y propaguen los ejercicios de la misma. Además, la considera como medio que, según el sentir de la Iglesia, responde de modo peculiar a las necesidades de nuestro tiempo y prepara y promueve con mucha diligencia el advenimiento del Reino de Dios al mundo.

A su clamoroso y meteórico triunfo contribuyeron varios factores, entre los que sobresale, sin duda, El Mensajero del Corazón de Jesús, órgano de difusión específico, común y universal que le acompañó desde sus comienzos y que todavía hoy se sigue editando con el título simplificado de Mensajero. Pero también buena parte del éxito del apostolado se debió a las propias características de su organización, cuya flexibilidad favorecía su presencia en toda la sociedad. Así lo describió su fundador (Ramière 1865: 399 y 402):

El Apostolado de la Oración no es una congregación ni una cofradía propiamente dicha, sino una liga de celo y de oraciones a la cual son invitados a inscribirse todos los cristianos [...]. Es una grande liga, en la que entran en masa, y sin cambiar nada de su respectiva organización, las sociedades piadosas ya establecidas en el seno de la Iglesia. Cada una de estas sociedades sigue consagrándose al objeto que le es peculiar, y al entrar en el Apostolado, ninguna nueva añade a las de su instituto: basta con dirigir las obras propias de su vocación a las intenciones del Corazón de Jesús.

Con el objetivo último de reforzar la devoción en medio del creciente laicismo de la sociedad europea, también Pío IX instituyó en 1856 la cele- 
bración festiva del Sagrado Corazón de Jesús en la Iglesia Universal. Y en 1875 promulgó la consagración definitiva de la Iglesia al Sacratísimo Corazón. En el caso de nuestro país, estas iniciativas encajaron con gran comodidad en una sociedad en la que el catolicismo no sólo había afianzado sus posiciones, merced al concordato firmado con la Santa Sede en 1851, sino que, además, se mostraba cada vez más politizado. Así, la devoción al Sagrado Corazón se vio sometida a interesadas manipulaciones, poniéndose al servicio, en apariencia de manera exclusiva, de determinadas facciones que sostuvieron una reiterada lucha por el poder a lo largo de toda la centuria: el caso de los carlistas es, en este sentido, paradigmático. Con tales antecedentes, la denominada "cuestión religiosa", que provocó enconados enfrentamientos entre liberales y conservadores en los años de la Restauración alfonsina y que coincidió en el tiempo con la reafirmación del poder de la Iglesia en España, tuvo precisamente uno de sus puntos más conflictivos en la ostentosa exhibición de que hacía gala la devoción que nos ocupa. De este modo, cuando el siglo XIX estaba a punto de finalizar, estaban sentadas definitivamente las bases de lo que sería el culto al Sagrado Corazón durante las décadas siguientes.

A pesar de la oposición que ejercieron los sectores liberales, las actividades puestas en marcha y alentadas por parte de la cúpula de la jerarquía eclesiástica fueron aplaudidas y secundadas por amplias capas de la población española. En 1899, León XIII proclama la consagración del mundo al Sagrado Corazón de Jesús a través de la encíclica Annum Sacrum. En el mismo año, la Sagrada Congregación de Ritos aprueba las Letanías del Sagrado Corazón, que desde entonces iban a figurar en todos los misales y devocionarios. Y,

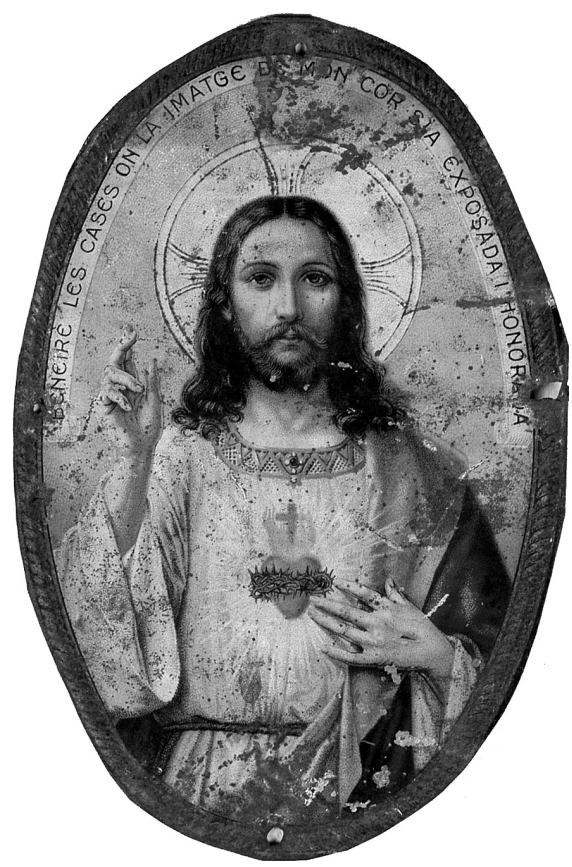

FIG. 1. Placa para puerta (ca. 1920). MT096914 por si todo ello no bastara, como réplica a las celebraciones del centenario de la Revolución Francesa, surgió una corriente que impulsaba la consagración de naciones, familias, hogares y entidades de todo tipo al Sagrado Corazón. 
Puesto que la intención de esta política era, en definitiva, hacer pública y permanente confesión del vínculo con el Sagrado Corazón, es en estos momentos cuando adquieren forma definitiva dos objetos que analizaremos más adelante y que, en nuestra opinión, encarnan la devoción que nos ocupa. Se trata, por un lado, de los denominados detentes y, por otro, de las placas para las puertas (fig. 1). Porque estas últimas se convirtieron — sin duda alguna de manera involuntaria- en el centro de una agria polémica y, como señala Callahan (2003: 56-57), fueron el origen último de un sinfín de disturbios que prendieron por todo el país:

Las placas pasaron a ser el símbolo en torno al cual lucharon los defensores y los adversarios de la Iglesia durante el agitado verano de 1899. Cuando las autoridades de Castellón decidieron retirarlas, hubo numerosas protestas por parte del clero y los feligreses locales. Manifestantes que llevaban la insignia del Sagrado Corazón recorrieron las calles de la ciudad y chocaron con los anticlericales en medio de un aluvión de bastonazos y pedradas. [...] Los desórdenes de Castellón y otras ciudades pusieron al gobierno de Silvela en una situación embarazosa. Aunque defendió el derecho de los católicos a poner las placas, también recomendó prudencia a las autoridades eclesiásticas.

A pesar de la crispación del ambiente, parece que la repercusión en España de la encíclica Annum Sacrum fue inmediata, ya que en 1900 se concibió la idea de erigir un monumento al Corazón de Jesús. Las dos décadas que transcurrieron hasta que el proyecto se hizo realidad no fueron baldías, puesto que permitieron abonar convenientemente el terreno. Así, en 1911 tuvo lugar la consagración oficial de España al Sagrado Corazón y un lustro más tarde se puso la primera piedra del conjunto del Cerro de los Ángeles. Se iba a levantar, en un emplazamiento profundamente emblemático por ser el centro geográfico del país, un altar, símbolo de la entronización del Corazón de Jesús en el corazón de España. Sectores muy influyentes de la sociedad española acogieron con entusiasmo una idea que, además, iba a ser íntegramente financiada mediante suscripción pública. Las aportaciones económicas fueron cuantiosas y, lo que es más significativo, fueron realizadas por los más diversos estamentos, desde el Papa hasta la familia real, pasando por multitud de centros oficiales, colegios, comunidades religiosas, colectivos laborales, asociaciones piadosas y particulares, tanto de España como de las antiguas colonias (Anónimo 1920). Tal como afirma Callahan (2003: 212), el 30 de junio de 1919 quedó oficialmente consagrado el lugar:

Aunque el sistema político de la Restauración se tambaleaba bajo el peso de los problemas acumulados, el rey Alfonso XIII, el jefe del gobierno, Antonio Maura, y una serie de notables, "cerrando los oídos a campañas tenaces, a huelgas espantables y a amenazas revolucionarias", se reunieron para la ceremonia. 
Como eco de este gesto, los años siguientes conocieron una auténtica fiebre por levantar, a lo largo y ancho de todo el país, monumentos similares, si bien más modestos en dimensiones y en repercusión. Este fue el comienzo de una campaña que bien podría calificarse de "colonización del territorio” y que alcanzó su punto culminante en la década de 1930, cuando se inició la construcción de dos emblemáticos templos dedicados en exclusiva al Sagrado Corazón. El modelo a seguir era el de la parisina basílica del Sacré Coeur, levantada en Montmartre tras los desastres de 1870 y también conocida como del "voto nacional". Así, en Barcelona se erige el Templo Nacional Expiatorio del Tibidabo, y en Valladolid la denominada Basílica de la Gran Promesa, proyectos ambos intrínsecamente grandiosos, cualidad que la propia arquitectura subrayaba y que sus respectivos órganos de difusión proclamarían sin cesar.

Pero los años de la Guerra Civil dejaron una huella indeleble en los tres hitos citados: el Cerro de los Ángeles fue destruido por completo y el templo de la ciudad condal quedó seriamente dañado, mientras que la inauguración oficial del santuario vallisoletano debió posponerse hasta 1941. La alta jerarquía eclesiástica y la cúpula militar del ejército de Franco utilizaron enseguida estos sucesos para sus propósitos doctrinales, merced a lo cual el Sagrado Corazón de Jesús acabó convertido en un símbolo nacionalista, defendido — supuestamente- por unos del mismo modo que -supuestamente- era agraviado por otros. De ahí que, prácticamente desde el inicio de la guerra, se prodigaran en el bando nacionalista los discursos, las alocuciones y los textos publicados que aunaban, bajo el nombre de España, los conceptos de patria, catolicismo y reinado del Corazón de Jesús. Las palabras pronunciadas en octubre de 1936 por el arzobispo de Valladolid y principal impulsor del Santuario Nacional de la gran Promesa, Remigio Gandásegui ${ }^{5}$, ejemplifican a la perfección el mensaje dominante:

En esta hora decisiva para los destinos de nuestra querida Madre España, cuando frente a las hordas sin Dios y sin Patria ofrendan su vida todos los españoles dignos de serlo, al servicio de la Cruz de Cristo y de nuestra gloriosa bandera roja y gualda, cuando la fe y el patriotismo hacen brotar legiones de héroes en las filas del Ejército y de las milicias para defender el secular patrimonio de la España católica, madre de los pueblos y fuente abundosa de civilización cristiana, sería un crimen de lesa fe y lesa Patria permanecer en actitud expectante, limitándose

${ }^{5}$ Hay que señalar que este mismo discurso fue publicado con el título: "Por el reinado del Sagrado Corazón de Jesús en España”, en Reinaré en España, año XXXVI, n.․․ 259, 1969, pp. 175-178. Era éste un número extraordinario de la revista con motivo del L Aniversario de la consagración de España al Sagrado Corazón de Jesús. Aunque habían pasado más de treinta años, tal reedición muestra que las consignas y conceptos, emitidos y controlados por el régimen, no habían variado un ápice. 
a admirar los triunfos de nuestras armas, o a estériles lágrimas por los que sucumben en la lucha. [...] España, la sana y verdadera España cuyos soldados y milicias han esmaltado las más heroicas páginas de bravura con su generosa sangre en esta guerra de reconquista patria y mundial contra los precursores del Anticristo, tiene también que hacer honor, una vez más, a su piadoso abolengo en esta cruzada de oración a la que nos invita el propio Corazón Divino y de la que nadie estará dispensado porque a todos alcanza la consoladora promesa "Reinaré en España y con más veneración que en otras partes".

En plena contienda, las posiciones ya eran firmes, como muestra el cardenal Isidro Gomá y Tomás, arzobispo de Toledo y Primado de España, en el artículo "El Corazón de Jesús, 'corazón de España”" (1937: 193-194), que incide en idénticas cuestiones:

[...] España, en un arranque genial, se consagró oficialmente a Jesucristo teniendo a gala servir de escabel a la gloria del Sagrado Corazón. La revolución, en otro arranque, pero diabólico, quiso sintetizar sus ideales fusilando la dulce imagen del Corazón de Jesús, que se erguía, por voluntad de España, en su centro geográfico. Hoy en España, como a lo largo de la Historia, las fuerzas antitéticas del bien y del mal se polarizan en torno a Jesucristo "señal de contradicción". Pero Jesucristo se muestra en este caso con su corazón patente, destilando sangre redentora, coronado de espinas de agravios y defecciones, inflamado en llamas purificadoras de las maldades del mundo. Y mientras los unos no pueden resistir la dulzura de aquella mirada y pretenden en su locura hacer saborear a Jesús las amarguras de su Pasión, otros ansían hacer un monumento en cada hogar y un altar al Sagrado Corazón en cada pecho.

Así pues, finalizada la guerra, el terreno estaba convenientemente abonado para que prosiguiera, e incluso se incrementara, la utilización de la devoción al Corazón de Jesús por parte del régimen franquista, proyectado ahora en el llamado nacionalcatolicismo. En este contexto se impulsó la reconstrucción inmediata del arrasado Cerro de los Ángeles, convertido en el símbolo por excelencia del proclamado anticlericalismo de la República. La oleada de restauraciones, lo mismo que la colocación de monumentos donde antes no existían, se extendió por todo el país durante las décadas de 1940 y 1950, alentada por las máximas autoridades civiles y religiosas, iniciativas ambas que crearon el clima adecuado para renovar la devoción $\mathrm{y}$, en particular, sus manifestaciones externas. A este ambiente propicio también contribuyó la encíclica de Pío XII Haurietis Aquas, un documento que, en opinión de muchos, supone el más profundo fundamento teológico y la defensa más intensa del culto que nos ocupa (Cerro Chaves 2001: 104-105).

Pues no faltan quienes, confundiendo o equiparando la índole de este culto con las diversas formas particulares de devoción, que la Iglesia aprueba y favorece sin imponerlas, lo juzgan como algo superfluo que cada uno puede practicar, o no, según le agradare [...]. Y no faltan quienes estiman que este culto, lejos de 
ser un poderoso medio para renovar y reforzar las costumbres cristianas tanto en la vida individual como familiar, no es sino una devoción, más saturada de sentimientos que constituida por pensamientos y afectos nobles, así, la juzgan más propia de la sensibilidad de las mujeres piadosas que de la seriedad de los espíritus cultivados.

En España, los momentos culminantes de esta nueva etapa tuvieron lugar en 1965, cuando Franco reinauguró el Cerro de los Ángeles en medio de manifestaciones de entusiasmo y fervor (Pascual 1965), y en 1969, al conmemorar en ese enclave el quincuagésimo aniversario de la adhesión de nuestro país a la figura del Sagrado Corazón de Jesús. Pero, indudablemente, no era oro todo lo que relucía, ya que, como ha apuntado Callahan, la ceremonia de 1969 fue la última de las grandes manifestaciones públicas de un nacionalcatolicismo que se había iniciado durante la guerra civil (2003: 389).

Los profundos cambios experimentados por la sociedad española desde entonces hasta finales del siglo xx fueron minimizando progresivamente el impacto de ésta y otras devociones, apenas visibles hoy en medio del laicismo propio de un Estado aconfesional. Es cierto, no obstante, que, al margen de la evolución y del desarrollo de las experiencias religiosas individuales y colectivas, en prácticamente todas las localidades del país perviven todavía un buen número de testimonios materiales de la íntima y particular identificación que se estableció entre el Sagrado Corazón y España ${ }^{6}$.

\section{ICONOGRAFÍA PARA UNA NUEVA PIEDAD}

Aunque, se trata de un culto tardío que, a diferencia por ejemplo de la Inmaculada Concepción de la Virgen, no ha originado ninguna obra de arte de primer orden (Réau 1983: 47), consideramos de enorme interés apuntar algunos rasgos de la iconografía del Sagrado Corazón de Jesús; figura que en el imaginario católico ha acabado ocupando un lugar verdaderamente preeminente. Ello se debe en buena medida a su posición cercana a las prácticas piadosas cotidianas y, en consecuencia, a la gran difusión que tuvo el icono. Por tanto, los mismos objetos de devoción se convirtieron en la mejor de las propagandas. Continuando con la comparación del Sagrado Corazón con la Inmaculada, vemos que las representaciones de ésta última no abundan demasiado, al margen de los encargos relacionados directamente con los monarcas hispanos de los siglos XVI, XVII y, quizás, del XVIII, así como

\footnotetext{
${ }^{6}$ Precisamente, uno de los trabajos seleccionados en la edición de 2007 del Certamen de Fotografía sobre Cultura Popular lleva por título Bendeciré. Su autor es Jesús Antonio Rodríguez Pérez, quien dirigió su objetivo a las placas de puerta del Corazón de Jesús (Certamen 2008: 221).
} 
con determinadas órdenes religiosas ${ }^{7}$. El motivo radica, en nuestra opinión, en que la Inmaculada siempre estuvo estrechamente vinculada con una cuestión dogmática, mientras que, desde el primer momento, el Sagrado Corazón se puso en relación con la piedad individual y humanizada, característica del siglo XIX.

En consonancia con el devenir histórico de los acontecimientos que hemos esbozado, el asunto del Sagrado Corazón de Jesús sólo entró definitivamente en el repertorio de la iconografía católica en la segunda mitad del siglo XVIII. Parece que el momento exacto coincide con la comentada aprobación del culto que sancionó Clemente XIII en 1765. Porque, en efecto, fue entre esa fecha y 1767 cuando Pompeo Batoni pintó para Il Gesù de Roma un óleo sobre cobre titulado El Sagrado Corazón de Jesús. El pintor presenta aquí un Cristo cardióforo, que lleva en su mano izquierda un corazón en llamas surmontado por una pequeña cruz y rodeado por una corona de espinas (Clark 1985: 306, n.o 303).

Muy poco tiempo después, en 1780, la reina María Francisca de Portugal encarga al mismo artista una obra sobre idéntico asunto para la basílica de la Estrella de Lisboa. Es entonces cuando el italiano firma un gran óleo que representa la Alegoría de la devoción universal al Sagrado Corazón de Jesús, cuya composición y desarrollo están inspirados directamente en las visiones de María Alacoque. La característica más destacada del lienzo es que, en esta ocasión, el corazón aparece aislado, separado del cuerpo de Cristo, emanando luz sobre el mundo que aparece a sus pies; además, como en la pintura anterior, está rodeado por la corona de espinas y surmontado por la cruz. En opinión de Réau, parece que la Congregación de Ritos prohibió muy pronto la iconografía del corazón aislado, una orden que sabemos que no siempre se cumplió (fig. 2), decantándose por representar el corazón aislado (Réau 1983: 49).

En efecto, como ya hemos apuntado, este último sirvió de inspiración a multitud de estampas abiertas en España desde finales del XVIII y durante la primera mitad de la centuria siguiente. También se utilizó en objetos de pequeño tamaño, como escapularios y detentes (fig. 3).

Sin embargo, la necesidad de dar forma a una imagen de culto, destinada en principio a ocupar un lugar preeminente en los templos y en los espa-

${ }^{7}$ Naturalmente esta reflexión no es válida si pensamos en la multitud de objetos con la efigie de la Inmaculada Concepción que se pusieron en circulación con motivo de la proclamación del dogma en 1854. Si bien es cierto que este repunte dio impulso a la devoción, también lo es que ésta se mantuvo relativamente poco tiempo en el punto de mira general. Las diferentes advocaciones marianas, de influencia local, regional e incluso nacional, acabaron desplazando a la Inmaculada. Por el contrario, el prestigio del Sagrado Corazón fue aumentando con el paso del tiempo. 


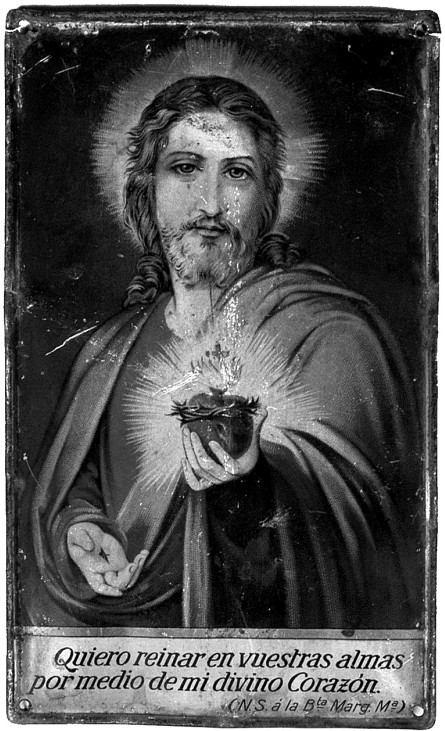

FIG. 2. Placa para puerta (ca. 1920). El Sagrado Corazón copia el modelo de Batoni. MT096911

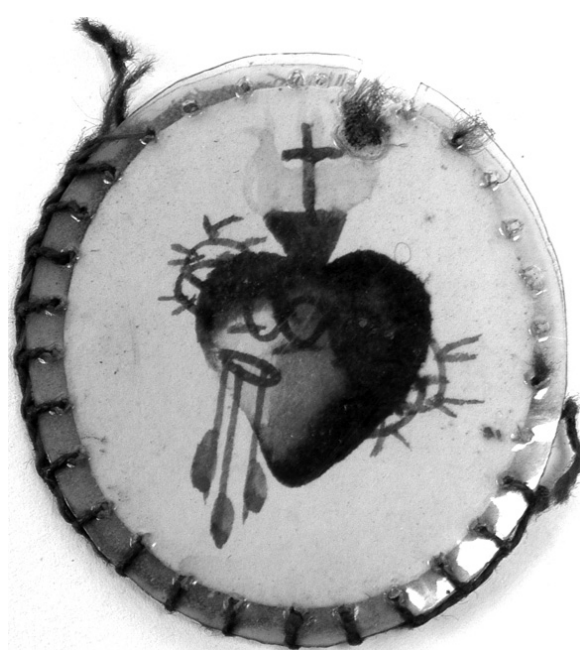

FIG. 3. Detente con el corazón aislado. MT098556

cios públicos, guardando siempre cierta sintonía formal con la imaginería tradicional católica, dio origen a un nuevo modelo. Ahora Cristo se presenta, bien con el corazón inflamado aplicado sobre el pecho, bien con una incisión rodeada de rayos en el mismo lugar. Esta figura está directamente inspirada en el Cristo que el danés Alberto Thorvaldsen había realizado en torno a 1825 para la catedral de Copenhague, una escultura de mármol de corte neoclásico. Representa a un Cristo de rasgos idealizados, que abre sus brazos en actitud de acogida. A partir de esta efigie se recreó otra con el corazón explícito, la cual fue policromada - mejor dicho, coloreada- siguiendo unas pautas vagamente barrocas. Esta iconografía es la que ha venido reproduciéndose masivamente y sin solución de continuidad desde finales del siglo XIX, tanto en España como en Francia, países donde el Sagrado Corazón alcanzó mayores cotas de popularidad, y en Iberoamérica. Desde el punto de vista de la historia del arte, se trata de una iconografía poco afortunada, muy alejada de las pautas del arte religioso moderno (fig. 4). Pero lo cierto es que su omnipresencia acabó minimizando la influencia positiva que pudieron haber ejercido otros modelos elaborados por artistas más innovadores, que los hubo: no cabe duda de que la mayoría de los fieles acabó demandando el modelo oficial, que terminaría por imponerse ${ }^{8}$.

\footnotetext{
${ }^{8}$ Parece, no obstante, que se intentó buscar un modelo iconográfico más acorde con los tiempos. Aunque no hemos podido averiguar ningún dato acerca de la nómina de
} 


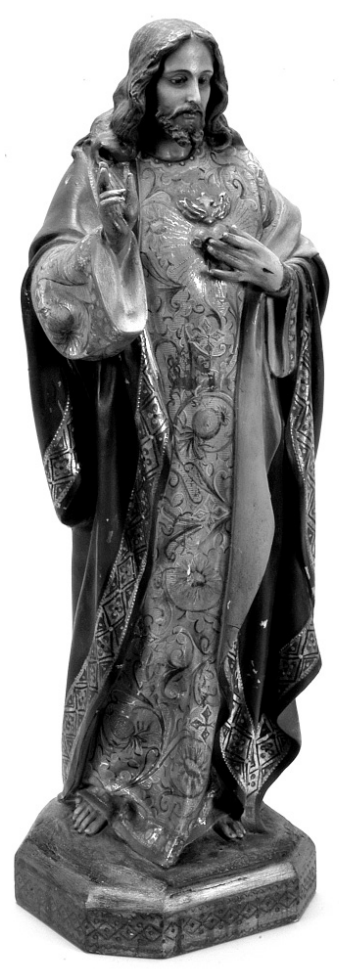

FIG. 4. Imagen de devoción doméstica (ca. 1940). MT096983

Así pues, tanto el corazón aislado, como la imagen de Cristo mostrando o insinuando su corazón son los iconos que mejor condensan la esencia de este culto. Por tanto, son los que figuran en los numerosos objetos de devoción relacionados con él, y que hoy forman parte de la colección del Museo del Traje. Centro de Investigación del Patrimonio Etnológico. En algunos casos se trata de representaciones destinadas a implantar el culto o, en su caso, a reforzar su presencia. Opinamos que este sentido tiene, por ejemplo, su incorporación al reverso de numerosísimas medallas marianas españolas e iberoamericanas, hecho que debe situarse, en la mayoría de los casos, entre 1911, fecha de la consagración oficial de España, y la inauguración del Cerro de los Ángeles en 1919. En la misma línea cabe situar las cromolitografías, aleluyas de santos, benditeras y un largo etcétera.

Pero en otras ocasiones los objetos de devoción son mucho más que un mero vehículo propagandístico, ya que en ellos se condensan de forma admirable los abstractos fundamentos teológicos. A esta categoría pertenecen los detentes, los escapularios y las placas para las puertas, algunas de cuyas características expondremos a continuación.

artistas ni las características de sus trabajos, Mundo Gráfico en su número 943 (noviembre de 1929) insertaba la siguiente noticia: "Una entidad barcelonesa ha organizado un concurso internacional de imágenes del Sagrado Corazón, ofreciendo el premio "Pater Misericordiae", consistente en 50.000 pesetas en oro. En el Palacio de las Artes Decorativas de la Exposición se exhiben ochenta y dos obras de aspirantes al premio. Entre los escultores que han acudido al concurso hay españoles, franceses, italianos, colombiano, alemanes, brasileños, daneses, belgas, polacos, suizos y húngaros". 


\section{EL DETENTE}

El detente, pese a ser un objeto no del todo desconocido, pocas veces se ha estudiado, y cuando ha sido objeto de investigación siempre parece que ha prevalecido su carácter de pieza menuda del imaginario popular. Así, Llompart (1968) definió el detente como un preservativo, un protector sagrado que suponía el punto final de una larga serie de objetos que, desde la Edad Media, habían venido usando los católicos con la autorización más o menos explícita de Roma. Por su parte, Labude de Krugel (1983) se refiere a él como objeto de decoración popular del que se conoce una gran variedad de modelos. En nuestra opinión, formada teniendo en cuenta la trayectoria seguida por el catolicismo, el detente es el objeto que materializa, mejor que ningún otro, la devoción al Sagrado Corazón. Su plena difusión en España se inició en las décadas finales del siglo XIX, bajo los auspicios de Pío IX, siendo acogido por igual en todas las clases sociales. Así lo atestiguan los distintos artículos publicados al respecto en Mensajero del Corazón de Jesús. El primero de ellos en el tiempo se titula "El escapulario del Corazón de Jesús" y es una traducción del original francés (Anónimo 1873: 219-222). Se trata de un texto largo, que ofrece no sólo algunos apuntes históricos, sino también instrucciones detalladas sobre su forma, la cual recuerda vagamente a un escudo:

Su origen no se remonta más allá del siglo pasado. Asolaba la peste en Marsella en año 1720, cuando una santa religiosa del monasterio de la Visitación, establecido en aquella ciudad, supo por revelación divina que el mejor preservativo contra aquel terrible azote sería llevar sobre el pecho la imagen del Sagrado Corazón de Jesús acompañada de esta breve inscripción: Detente, el Corazón de Jesús está conmigo. Manifestó la santa religiosa a sus demás compañeras esta revelación, y bien pronto cumplida por muchas personas devotas de la ciudad infestada, viéronse los palpables efectos de aquella saludable enseña, que preserva del contagio de la peste a los que la llevaban sobre su cuerpo.

Después de la muerte de la fundadora, que murió en olor de santidad, se conservó el escapulario como una devoción privada, hasta que el cólera, que invadió la ciudad de Amiens en 1865, hizo revivir sus públicos beneficios, propagándose su uso entre toda clase de personas.

Durante la guerra entre Francia y Prusia, las señoras de la primera de estas naciones se dedicaron a propagar la devoción al sagrado escapulario, habiéndose visto en los campos de batalla extraordinarios prodigios en los soldados que le llevaban sobre su pecho.

Deseando últimamente una señora romana conocer la opinión de Pío IX acerca de esta devoción, le ha presentado un escapulario y Su Santidad, conmovido a la vista de este signo de salvación, ha exclamado: "Señora, es un pensamiento del cielo....Sí; viene del cielo". Después el Papa se dignó concederle su bendición, y añadió: "Quiero que todos los escapularios que se hagan por este modelo parti- 
cipen de esta bendición, y que las asechanzas del demonio no alcancen a los que le coloquen sobre su pecho".

Pío IX envió dos de estos escudos o escapularios a un convento de religiosas en Roma manifestándoles el deseo de que hiciesen muchos para distribuirlos a los fieles, y extender por este medio la devoción al Sagrado Corazón de Jesús; de Roma se han propagado por España y otras naciones, y están haciendo prodigios.

A diferencia de lo que sucede con los escapularios de otras advocaciones, que se ponen al cuello pendientes de un cordón, el del Sagrado Corazón de Jesús consiste en un cuadrilongo de lana blanca de 8 centímetros de largo por 6 de ancho, poco más o menos, en cuyo centro hay un pequeño corazón de lana encarnada, atravesado por una corona de espinas hecha con seda verde, rematando con una pequeña cruz de seda negra, y en la parte inferior la leyenda impresa en una pequeña pieza de lana blanca, unida a la de lana con una costura de sedas de colores. Este escapulario se cose o prende con alfileres interior o exteriormente a cualquiera prenda del vestido, de modo que esté junto o sobre el corazón. Puede también construirse de papel para poner en las puertas y ventanas; y quien lo usa debe rezar diariamente tres veces el Padrenuestro, Avemaría y Gloria en honor del Sagrado Corazón de Jesús, por la cruz, corona y llaga con que está marcado.

Puede cualquiera construir estos corazones, y Su Santidad ha concedido que queden benditos al dar la última puntada.

Tanto en este primer momento, como en los años sucesivos, el detente del Sagrado Corazón de Jesús se denomina, indistintamente, escapulario, preservativo, salvaguarda o, simplemente, imagen. Así, entre las indulgencias aprobadas en 1952 para los asociados al Apostolado de la Oración, la parcial de cien días se gana, entre otras ocasiones, "siempre que asistan a preces públicas ostentando en su pecho la imagen del Sagrado Corazón de Jesús" (Ibid:: 14). En esta ocasión, como en otras muchas, tampoco queda claro si la imagen en cuestión se refiere al escapulario clásico o a otra divisa más específica.

Pero lo cierto es que dicho distintivo se conoce tradicional y popularmente con el nombre de detente. Parece que este término fue acuñado en el último cuarto del siglo XIx, de forma paralela a la expansión y consolidación de la devoción. Es el último estadio de la sustantivación del imperativo que encabeza la conocida exhortación "Detente, el Corazón de Jesús está conmigo", y se acaba convirtiendo en un resumen de ésta. Es difícil precisar el momento exacto de su adopción, aunque parece plausible situarle muy cerca de la publicación, junto al citado artículo sobre el escapulario de 1873 , de una curiosa poesía de autor no identificado —imitación del himno francés Arrete!- que lleva por título ;Detente, enemigo!?

\footnotetext{
${ }^{9}$ El Mensajero del Sagrado Corazón de Jesús, T. XVI, 1873, pp. 278-279.
} 
El centenar de detentes que conserva el Museo del Traje, Centro de Investigación del Patrimonio Etnográfico, nos ha servido para trazar sus características formales a lo largo de un período que va desde 1877 hasta 1996, fecha en la que se adquirió en el mercado una pieza contemporánea. Porque, no hay que olvidar que el detente todavía se fabrica, se vende o se obsequia, y, en definitiva, se utiliza. Si bien en un principio se siguieron al pie de la letra las recomendaciones publicadas, parece que muy pronto se introdujeron variaciones en el modelo propuesto, algo que no debe extrañarnos si tenemos en cuenta la multitud de manos femeninas - casi siempre monjas de clausura- que, a lo largo de más de cien años, intervinieron en su confección.

Los materiales más utilizados fueron lana blanca y, posteriormente, papel (recubierto de plástico en los ejemplares más recientes). En cuanto a su forma, puede ser romboidal, oval, circular o cuadrangular; geometrías que se rematan con un borde liso, ondulado o en forma de dientes de sierra (fig. 5). A fin de facilitar su disposición entre la ropa y otros efectos personales, el tamaño del objeto era pequeño, oscilando entre 2 y $10 \mathrm{~cm}$. de altura y entre 2 y $9 \mathrm{~cm}$. de ancho. La misma intención se presume en las ocasiones que adoptaba la forma de una cartera o bolsa cerrada. Una superficie tan reducida exigía un motivo iconográfico acorde, de manera que, como hemos mencionado, se optó por el corazón aislado. En cuanto a las técnicas decorativas, los detentes de lana solían estar bordados con sedas de colores, aunque no es infrecuente que el motivo aparezca pintado. Los fabricados en papel utilizaban las técnicas habituales de impresión.

Como complemento textual de la imagen del corazón, el detente incorpora la mencionada leyenda "Detente, el corazón de Jesús está conmigo". No obstante, es importante señalar que esta invocación puede aparecer sola o acompañada de otras frases relacionadas con diversos momentos significativos de la historia de la devoción. De ahí que sean varias las combinaciones de texto que pueden figurar en los detentes (fig. 6): "Detente, el corazón de Jesús está conmigo /Venga á nos el tu reino", "R. / E." [Reinaré en España], "Detente, el corazón de Jesús está conmigo", "Detente, el corazón de Jesús está conmigo / Reinaré en España", "Detente, enemigo, que el Sagrado Corazón de Jesús está conmigo", "Cristo Reina”, etc.

En España el uso del detente conoció dos momentos de especial esplendor, ambos relacionados con conflictos militares. El primero de ellos se sitúa en la tercera guerra carlista, mientras que el segundo transcurrió durante los años de la Guerra Civil. Al igual que ocurrió con otros símbolos religiosos, parece claro que el ejército franquista hizo todo lo posible por apropiarse en exclusiva del detente. Así, por ejemplo, el maestro del realismo épico Carlos Sainz de Tejada muestra en muchas de sus ilustraciones 


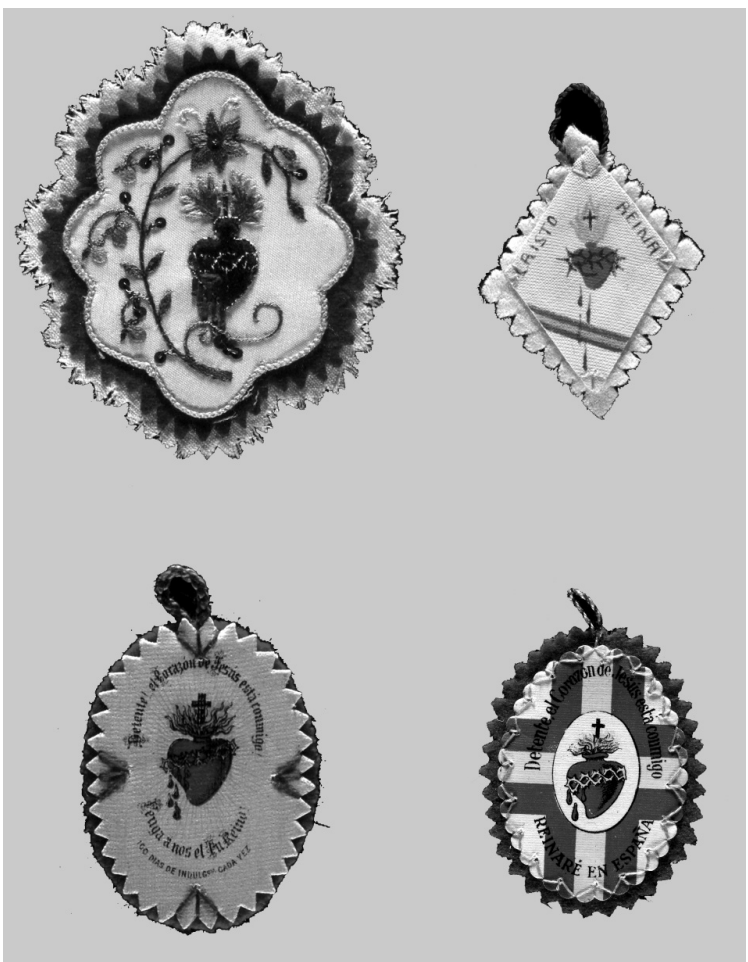

FIG. 5. Varios modelos de detentes (ca. 1875-1975). MT081034, 081040, 086152 y 042856

FIG. 6. Detente (ca. 1996).

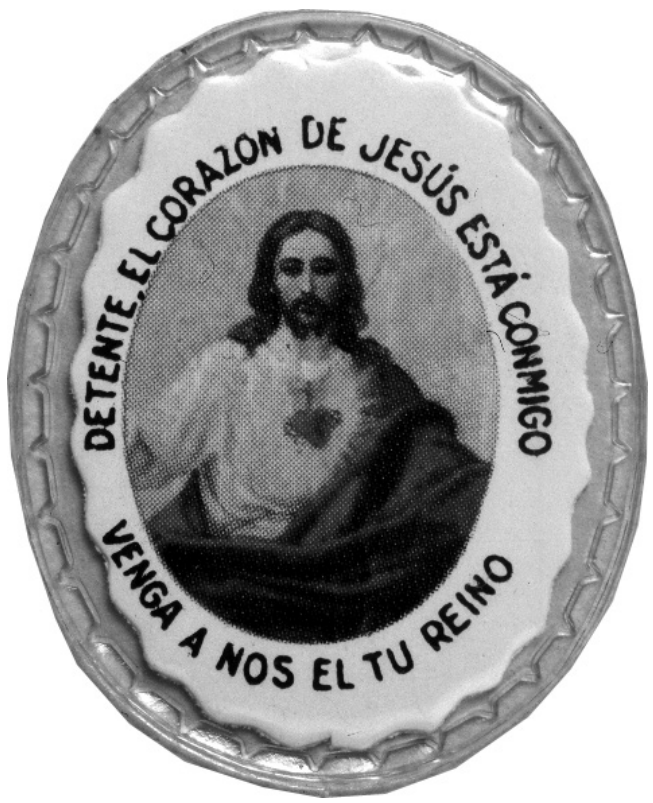


los detentes bien visibles sobre el lado izquierdo del uniforme de los soldados rebeldes. Sabemos, no obstante, que fueron muchos los casos que echaban por tierra esa simplista dicotomía. Quizá uno de los testimonios más ilustrativos del sentido que tenía el detente en la España de la época sea el que recoge Ian Gibson (1980: 117-118). Los hechos se relacionan con la detención de César Torres Martínez, Gobernador Civil de Granada cuando estalló la contienda, con el posterior consejo de guerra al que fue sometido el detenido, y con sus ocho años de estancia en prisión:

En la cárcel de Granada [en agosto de 1936] tuvo lugar en tales circunstancias una extraordinaria floración de religiosidad. Como los nacionalistas se declaraban soldados de una cruzada católica contra los enemigos de Dios, era sumamente prudente, además de psicológicamente comprensible declararse, y sentirse, católico en aquellos momentos. Era como si, siendo - y siendo reconocido- católico, hubiese más posibilidades de sustraerse a la muerte. Sabemos, además, que muchas víctimas de los pelotones gritaban antes de caer: "soy inocente, soy católico". [...] A propósito de los detentes, Torres Martínez recuerda unos detalles que expresan gráficamente la superstición religiosa de la cárcel y el temor a la muerte que llenaba entonces todas las almas:

La primera vez que oí hablar de los detentes fue después de tomarme declaración el juez. El secretario, el que escribió a máquina, era un chico joven, muy agradable, vestido con una camisa azul, pero muy buena persona, muy agradable, porque, al marcharse — primero salió el juez, yo me quedaba allí para marcharme a mi celda después—, ese señor, al recoger la máquina, me dice: “¿A usted le molestaría mucho llevar un detente, llevar este detente?" Yo dije: "No, claro, ¿cómo me va a molestar llevar este detente?” Y me lo puse. Y, claro, jse dio la casualidad que de los que fuimos al consejo de guerra el único que se salvó fui yo! El segundo consejo de guerra se celebró, calculo yo el día 6 a 8 de agosto, contra seis elementos militares que consideraban como contrarios al Movimiento e izquierdistas. ¡Y se volvió a dar la misma historia! Porque el único que se salvó era el capitán, o comandante, don Bonifacio Jiménez que era de Intervenciones Militares, y que llevaba también un detente dado por la misma persona. Claro, yo después, los detentes he visto que tuvieron una floración extraordinaria, extraordinaria. Porque todo el mundo andaba con detentes.

Entonces, pasados meses, vino un padre, el padre Rubio, a verme a la cárcel, y me dijo: "Mire usted, es que yo estoy investigando sobre la conducta de una monjita, mejor dicho, sobre las virtudes de una monjita, sor Cristina, que nosotros consideramos que es santa, es una mujer tan buena, y parece que usted llevaba un detente, ¿es verdad esto?" "Sí, pues lo llevaba y es éste, claro", y se lo enseñé. Dice: "Pues este detente lo hizo sor Cristina". Dije: "Pues muy bien", pero yo no sabía ni quién era sor Cristina. Dijo él: "Y da la circunstancia notable de que el otro que se salvó en el segundo consejo de guerra también llevaba un detente de sor Cristina". Pues aquel padre me dice esto. Y a las pocas semanas esta propia sor Cristina me mandó una imagen, escrita de su puño y letra, diciendo "orar, rezar y sufrir" o un lema parecido, y yo la tenía en mi celda, y me parece que la conservo todavía. 
Testimonios similares, que no fueron infrecuentes en los años difíciles de la guerra y de la primera postguerra, tuvieron un eco formidable en el politizado panorama nacional, contribuyendo a propagar los beneficios de la devoción al Sagrado Corazón de Jesús.

\section{EL ESCAPULARIO}

Mientras que el detente se presenta como un objeto específico de la devoción que nos ocupa, el escapulario es, en esencia, una insignia vinculada a la Virgen del Carmen y, por extensión, a multitud de santos y de advocaciones marianas (Herradón Figueroa 2001). El escapulario del Sagrado Corazón de Jesús guarda relación directa con el mencionado Apostolado de la Oración, aprobado en 1846 por Pío IX, pero cuya divisa específica se configuró algo después, ya que fue sancionada el 14 de junio de 1877. Por tanto, es algo posterior en el tiempo al detente, lo que podría significar los esfuerzos realizados por la Iglesia para disponer de un emblema de sólida tradición, de fácil reconocimiento y, lo que es más importante, desprovisto de las posibles connotaciones irracionales - y, porqué no decirlo, supersticiosas- que pudiera adoptar o haber adoptado por entonces el detente ${ }^{10}$. Por sus características formales, además, el escapulario era visible, una condición que en los detentes no era indispensable.

Desde el momento de su aprobación, la revista El mensajero del Sagrado Corazón de Jesús publicó en repetidas ocasiones las características formales de este escapulario, a fin de garantizar un aspecto correcto y, sobre todo, uniforme (G. R. C. 1888: 472):

La insignia y divisa del Apostolado de la Oración, aprobada por Pío IX en el rescripto de 14 de julio de 1877, consiste en la imagen del Corazón de Jesús, pintada, litografiada o bordada sobre tela, con esta inscripción: VENGA Á NOS EL TU REINO -ADVENIAT REGNUM TUUM.

Nuestra insignia no es en rigor un escapulario, sino basta que tenga la forma de escudo, con tal que éste lleve las condiciones necesarias: primero, tener la imagen del Corazón de Jesús; segundo, que se halle en él la inscripción dicha. En España lo generalmente adoptado en casi todos los centros del Apostolado es coser

${ }^{10}$ Fueron numerosos, por ejemplo, los textos que publicitaron la acción beneficiosa de los detentes en las epidemias de peste y de cólera que asolaron Francia y España durante la segunda mitad del siglo xIX. Entre ellos destacamos el titulado "El Corazón de Jesús, gran remedio preservativo contra el cólera” (Anónimo 1885). Es posible que también la medalla del Apostolado de la Oración, de la que aquí no nos ocuparemos, se pusiera en circulación en 1868 con el mismo fin que el escapulario. Las medallas han sido, quizá, los objetos preferidos por los católicos para expresar sus preferencias devocionales. 
el escudo sobre franela blanca con seda o lana encarnada, y luego darle la forma de los escapularios propiamente dichos, uniendo esta divisa a otra piececita de lana blanca de igual forma o tamaño, por medio de dos cordones, o cintas, o trencillas de color encarnado, de lana o de seda.

Tampoco está prescrita la forma que se ha de dar al escudito o insignia. Unos, y son los menos, lo llevan en forma de corazón; otros cuadrado, pero lo más usado es que el escudito sea ovalado, y esté unido a un pedacito de franela cuadrada.

El resultado de estas recomendaciones fue un modelo único de escapulario, del que no conocemos ninguna variante en España. Es el que se ha venido utilizando en los actos públicos relacionados con el culto al Sagrado Corazón de Jesús y al igual que ocurre con todos los escapularios de gran tamaño, su visibilidad queda garantizada al disponerse obligatoriamente sobre la ropa (fig. 7).

\section{LOS ESCUDOS}

Como hemos venido repitiendo, la idea subyacente en todas las prácticas era hacer pública y permanente confesión de la devoción mediante procesiones y actos masivos, en los que detentes y escapularios se exhibían sobre el pecho. La implantación de ambos objetos a finales del siglo xIX era plena, y puede considerarse una suerte de prólogo a la aparición de otro nue-

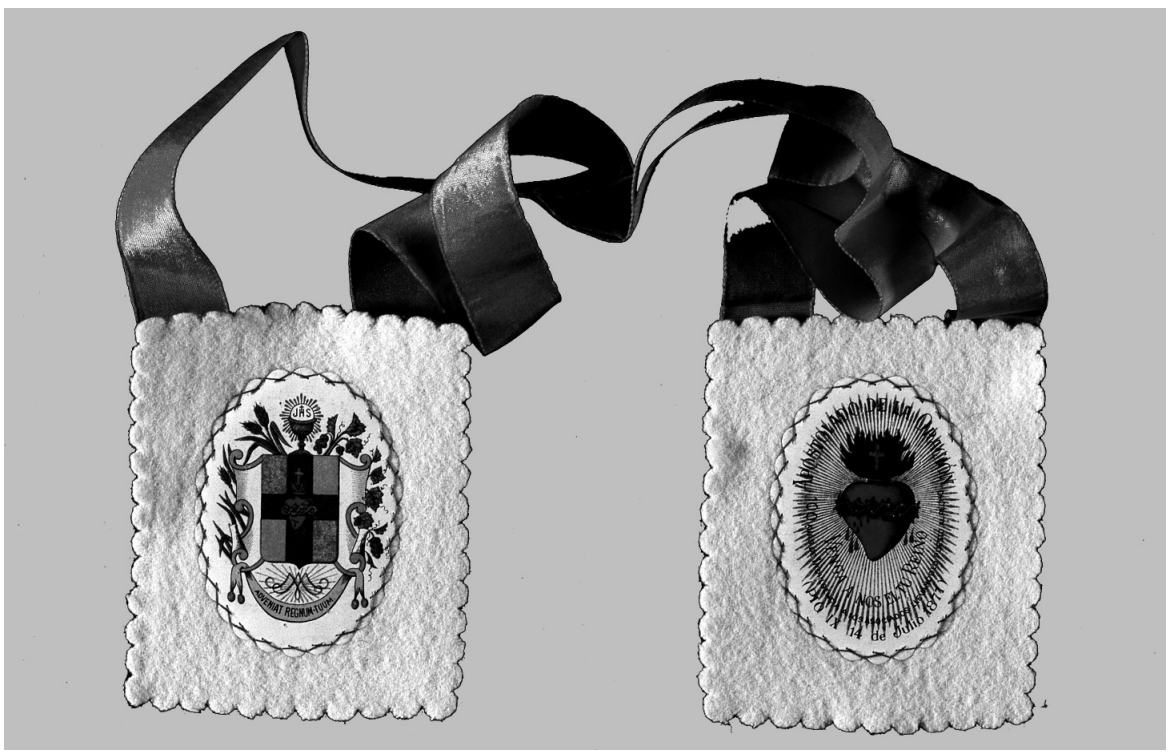

FIG. 7. Escapulario (ca. 1950). MT081062 
vo elemento, denominado en un primer momento escudo - en el sentido de emblema de identidad-, que iba a contribuir a significar aún más la piedad asociada con el corazón de Cristo (Anónimo 1899: 310-312). Es en esos momentos cuando aparecen en las puertas de las casas españolas las primeras placas con la efigie del Sagrado Corazón de Jesús:

Con motivo de la consagración del siglo xx a Jesucristo, Dios y Hombre verdadero y Rey de los siglos, ha surgido el hermoso pensamiento de fijar ostensiblemente en las fachadas de las casas un escudo del Corazón de Jesús, que será nuestro escudo de nobleza y significará la consagración pública de los moradores de esas casas al Corazón de Jesús, y la proclamación de su reinado social. [...] Si los predicadores apostólicos, si los misioneros, si los Directores diocesanos y locales del Apostolado de la Oración, si los Directores y Presidentes de otras asociaciones, hermandades y congregaciones católicas aceptan este hermoso proyecto y coadyudan a su realización, no dudamos que España se distinguirá entre todas las demás naciones por el culto público tributado al Rey de los siglos e Hijo de Dios, y que los albores del siglo xx sonrosearán con destellos de esperanza millones de escudos del Corazón de Jesús, enclavados en las fachadas de todas nuestras casas, desde la más humilde hasta la más suntuosa.

Y en nota a pie de página se complementa esta información con datos más específicos de los citados escudos, tales como características físicas, lugares de fabricación y precios:

El Obispo de Vich, fundador de El mensajero del Corazón de Jesús en España ha concedido cuarenta días de indulgencia a aquellos de sus diocesanos que teniendo dentro o fuera de sus casas el gran medallón de que hablaremos enseguida, digan las siguientes jaculatorias: iiSagrado Corazón de Jesús, salvadnos!! / iiGloria al Sagrado Corazón de Jesús!! / iiYo os adoro, oh Salvador del mundo!!

El medallón, que es de hierro, y mide 44 centímetros de alto por 30 de ancho, tiene de relieve el escudo de España, y en su centro, como protegiendo el escudo español, está la imagen compasiva y amorosa del Corazón de Jesús con esta inscripción debajo: Reinaré.

Se vende en Manresa en la fundición de Ubac, Miguel e Illa.-Carretera de Vic, núms. 47 y 49, y Sol, 1 , al precio de 7 pesetas bronceado, 9 plateado y 10 dorado. En una fundición de Eibar (Guipúzcoa) se están haciendo 50.000 placas de hierro esmaltadas con destino a Andalucía, especialmente a Cádiz. En ellas la imagen del Corazón de Jesús lleva al pie estas dos promesas de Jesús: Bendeciré las casas en las que la imagen de mi Corazón sea expuesta y honrada. Las personas que propaguen esta devoción tendrán escrito su nombre en mi Corazón, y jamás será borrado de él.

No vamos a insistir de nuevo en la polémica política que suscitaron y en la que se vieron envueltas tales placas, aunque sí queremos reiterar que se trata de objetos especialmente representativos de las características intrínsecas de la piedad relacionada con el Corazón de Jesús. Nunca antes en la larga historia del catolicismo se habían utilizado elementos similares, ni en 
la forma, ni en el mensaje, ni en el lugar de colocación, ni, por supuesto, en semejante cantidad. El Museo del Traje. Centro de Investigación del Patrimonio Etnológico conserva medio centenar de tales piezas, entre las que cabe distinguir las que presentan en bajorrelieve la silueta de la efigie — de cuerpo entero o de medio cuerpo- y aquellas que adoptan una forma plana - cuadrangular o en ojiva. En cuanto a las características técnicas de fabricación, se puede hablar de placas fundidas (en bronce y en aleaciones metálicas bañadas), de placas esmaltadas sobre hierro y de placas litografiadas sobre hojalata.

Este último grupo es el más numeroso, circunstancia que concuerda con las informaciones que se refieren a su distribución y colocación por millares, tanto entre 1900 y 1919, fecha de inauguración del Cerro de los Ángeles, como entre 1965 y 1969. Al igual que ocurría con el caso de los detentes, también las placas presentan una notable diversidad formal, lógica si se tiene en cuenta que los establecimientos litográficos que las fabricaron estaban distribuidos por todo el país. Sus dimensiones también son variables, oscilando entre 14 y $17 \mathrm{~cm}$. de altura, y entre 6 y $12 \mathrm{~cm}$. de ancho, del mismo modo que cambian las proporciones y ornamentos de la efigie. $\mathrm{Pa}$ rece, pues, que hubo cierta libertad a la hora de reproducir el icono; también las leyendas que lo acompañan —en castellano, catalán y vasco- muestran el ámbito local de su producción y distribución. De todo ello se desprende la perfecta adaptación del producto a una demanda muy amplia y heterogénea. Entre la nómina de fabricantes representados en la colección que nos ocupa destacamos Industrias Metalgráfica de Barcelona, Litografía La Atlántica de La Coruña, Litografía E. Muñoz de Vigo y Rochelt de Bilbao, que sobresale por haber sido la empresa que inició en España la estampación sobre hojalata de forma mecanizada y por su actividad continuada entre 1858 y 1983.

En la actualidad todavía son muchos los testigos materiales que quedan de esta práctica en todo el territorio nacional. Hemos constatado, sin embargo, que no sólo se usaron placas como las conservadas en el Museo. La tendencia era complementar las placas de metal — sin duda las más abundantes, ya que se fabricaron en serie- con las de otro tipo, recurriendo en estas ocasiones a materiales propios de la zona. Es el caso de las placas de cerámica turolense moldeada, que pueden verse todavía en muchas localidades de la zona del Maestrazgo, o de los cuadros de azulejos de cerámica talaverana que se usaron con idéntico fin en algunos pueblos toledanos. Todas las placas sin excepción siguen el modelo iconográfico clásico, que presenta a Cristo señalando su corazón o el lado izquierdo de su pecho (fig. 8).

Las placas de puerta constituían una irrefutable carta de presentación de la condición religiosa familiar, una declaración que podía ser considerada 

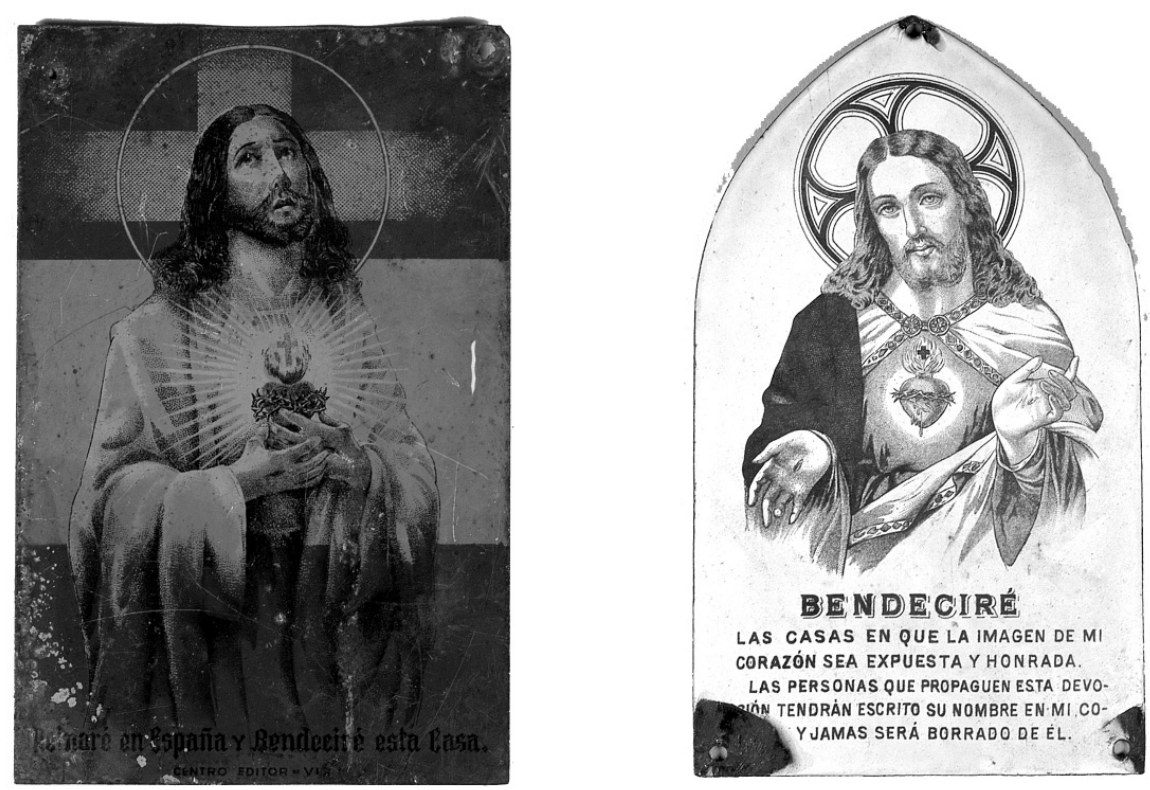

FIG. 8. Placas para puerta (ca. 1920). MT096912 y 096901

encomiable y positiva en según qué circunstancias políticas, pero que también podía suponer una condena en el más amplio sentido del término, según soplaran los vientos. Así, por ejemplo, lo recoge el relato que Pío Baroja (2006: 17-18) sitúa en Madrid cuando se proclamó la Segunda República:

En casa de un vecino de Carlos Evans [agregado militar en la embajada inglesa en Madrid entre 1932 y 1935, tiempo en el que vivió en la calle Fortuny], en el primer piso, en la puerta había un gran escudo del Sagrado Corazón de Jesús, a los pocos días de instaurarse la República ya no lo había.

—¿Qué le ha pasado a ese vecino? — preguntó Evans a la portera.

La noche de la proclamación de la República, estaba ese vecino con un destornillador quitando la placa de la puerta.

Aunque probablemente en ningún momento dejaron de instalarse esos escudos, pensamos que el segundo gran período de las placas de puerta con la efigie del Sagrado Corazón de Jesús debe situarse en torno a 1969, fecha de la reinauguración del monumento del Cerro de los Ángeles. En estos años, si bien persistieron tanto los materiales como los modelos iconográficos de comienzos de siglo, se advierte un cierto interés por innovar ambos aspectos (fig. 9). 


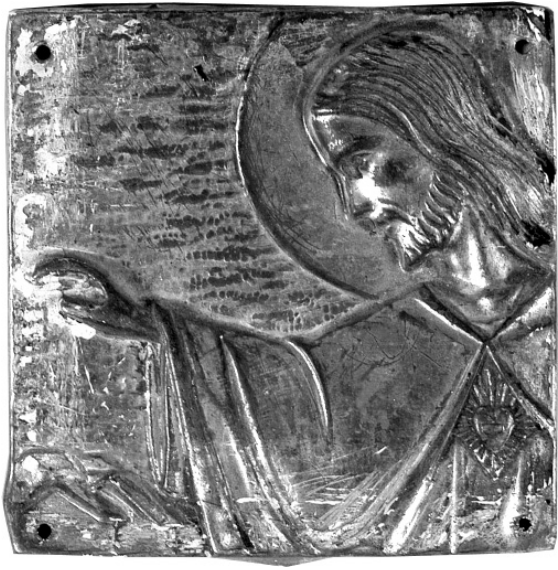

FIG. 9. Placa para puerta (ca. 1970). MT096884

A través de las cuestiones mencionadas en estas páginas hemos mostrado el proceso de introducción, adaptación y desarrollo que siguió en España la devoción al Corazón de Jesús. Su presencia alcanzó grandísimas cotas en todo el territorio, tanto en sus aspectos puramente devocionales como en su representación simbólica, debido a la activa intervención de diversos agentes sociales y a la conjunción de múltiples factores de índole política y religiosa. Pensamos que, tanto la complejidad del proceso, como su extensión en el tiempo y el espacio ilustran con nitidez hasta qué punto fue firme el compromiso - genuino, pero también impuesto- con las directrices de la jerarquía eclesiástica. Podemos concluir diciendo que, entre mediados del siglo XIX y mediados del Xx, la devoción al Sagrado Corazón de Jesús se consagró como una manifestación específica de la idiosincrasia religiosa española. No cabe duda, pues, de que la promesa proclamada por Bernardo de Hoyos, "Reinaré en España y con más veneración que en otras partes” acabó haciéndose realidad.

\section{BIBLIOGRAFÍA CITADA}

Anónimo. 1873. "El escapulario del Corazón de Jesús". El mensajero del Sagrado Corazón de Jesús XVI: 219-222.

Anónimo. 1875. "Escapulario del Corazón de Jesús". El mensajero del Sagrado Corazón de Jesús XIX: 99-103.

Anónimo. 1885. "El Corazón de Jesús, gran remedio preservativo contra el cólera". El mensajero del Sagrado Corazón de Jesús V: 175-181.

Anónimo. 1899. "Nuestro escudo de nobleza". El mensajero del Sagrado Corazón de Jesús XXVII: $310-312$.

Anónimo. 1920. El libro de oro de la piedad española. Relación del resultado de la suscripción pública para erigir el monumento al Sagrado Corazón de Jesús en el Cerro de los Ángeles. Madrid: Revista de Archivos, Bibliotecas y Museos.

Anónimo. 1942. Consagración del antiguo Reino de Valencia al Sagrado Corazón de Jesús ante su primer monumento reconstruido en España en Real de Gandía. Valencia: Imprenta Provincial.

Apostolado de la Oración. 1960. Estatutos del Apostolado de la Oración. Bilbao: El Mensajero del Sagrado Corazón de Jesús. 
Baroja, P. 2006. Miserias de la guerra. Madrid: Caro Raggio.

Callahan, W. J. 2003. La iglesia Católica en España (1875-2002). Barcelona: Crítica.

Cerro Chaves, F. (ed.). 2001. Encíclicas y documentos de los Papas sobre el Corazón de Jesús. Burgos: Monte Carmelo.

Certamen de Fotografía sobre Cultura Popular 2007. 2008. Madrid: Ministerio de Cultura, Subdirección General de Museos Estatales.

Clark, A. M. 1985. Pompeo Batoni. A Complete Catalogue of his Works with an Introductory Text. Oxford: Phaidon.

Decreto de la Sagrada Congregación de las indulgencias, relativo a las imágenes del Corazón de Jesús. 1878. El mensajero del Sagrado Corazón de Jesús" XXVI: 23-29.

G. R. C. 1888. "El escapulario del Corazón de Jesús propio del Apostolado". El mensajero del Sagrado Corazón de Jesús IV: 470-475.

Gibson, I. 1980. Granada en 1936 y el asesinato de Federico García Lorca. Barcelona: Crítica.

Herradón Figueroa, Ma A. 2001. "El escapulario, insignia de devoción mariana". Anales del Museo Nacional de Antropología 8: 145-198.

Jedin, H. (dir.). 1972. Manual de Historia de la Iglesia. 7 vols. Barcelona: Herder.

Labude de Krugel, C. 1987. "Dos objetos de la decoración popular poco conocidos: el Agnusdei y el Detente", en Etnología y Tradiciones Populares (Congreso de Zaragoza-Calatayud) II: 235-248. Zaragoza: Institución Fernando El Católico.

Loyola, J. de. 1831. Tesoro escondido en el Sacratísimo Corazón de Jesús descubierto á nuestra España en la breve noticia de su dulcísimo culto, Propagada ya en varias provincias del Orbe Cristiano. Madrid: Imprenta que fue de Fuentanebro.

Llompart, G. 1968. "Cabos sueltos de folklore religioso mallorquín". Revista de Dialectología y Tradiciones Populares XXIV: 35-56.

M. C. J. 1887. "El escapulario del Sagrado Corazón". El mensajero del Sagrado Corazón de Jesús III: 363-373.

Ortega Ayuso, L. 1959. El Sagrado Corazón de Jesús. Madrid: Instituto Nacional del Libro Español.

Pascual, P. 1965. El Cerro de los Ángeles. Madrid: Publicaciones Españolas.

Payne, S. G. 1984. El catolicismo español. Barcelona: Editorial Planeta.

Pérez-Rioja, J. A. 1984. Diccionario de símbolos y mitos: las ciencias y las artes en su expresión figurada. Madrid: Tecnos.

Queralt Teixidó, A. 2001. Pío IX, el Papa de la Inmaculada y del Sagrado Corazón. Barcelona: Apostolado de la Oración.

Ramière, H. 1865. El Apostolado de la Oración, santa liga de los corazones cristianos unidos al Corazón de Jesús. Barcelona: Magriñá y Subirana.

Réau, L. 1983. Iconographie de l'art chrétien. Vol. II, 2. París: Presses Universitaires de France.

Uriarte, J. E. de. 1880. Principios del reinado del Corazón de Jesús en España. Madrid: Imprenta a cargo de D. Blas María Araque.

Fecha de recepción: 17 de septiembre de 2008

Fecha de aprobación: 27 de junio de 2009 
